\title{
Determination of Local Stress Within Twins in a Twinning Induced Plasticity Steel
}

\author{
Bouaziz 0* \\ Laboratoire d'Etude des Microstructures et de Mécanique des Matériaux (LEM3), CNRS, Université de Lorraine, Arts et Métier Paris Tech, \\ France
}

*Corresponding author: Bouaziz O, Laboratoire d’Etude des Microstructures et de Mécanique des Matériaux (LEM3), CNRS, Université de Lorraine, Arts et Métier Paris Tech, France

\begin{abstract}
Thanks to the measurements of the Bauschinger effect and the twin volume fraction, the local stress within twins in Twinning Induced Plasticity (TWIP) steels has been experimentally determined. It is found that this local stress rapidly increases as a function of plastic strain to levels higher than $2 \mathrm{GPa}$ and can be probably higher than $3 \mathrm{GPa}$ for strains larger than 0.2. Mechanisms suitable to explain this order of magnitude are briefly discussed.
\end{abstract}

Keywords: TWIP, twin; Stress; Strain-hardening

\section{Introduction}

Discovered by Sir Robert Hadfield in 1881 [1], high manganese TWIP steels are currently one of the most attractive materials for structural applications in the automotive industry due to their unique combination of strength and elongation. The impressive strain-hardening of TWIP steels is the most studied mechanical characteristic of these alloys [2]. It has been reported that these alloys exhibit a very large Bauschinger effect [3-5], which is the signature of a strong heterogeneous distribution of local stresses in the microstructure. Due to the nanoscopic size of these induced twins, it can be assumed that the local stress within these twins is larger than the stress within the surrounding matrix, bringing about a large strain-hardening with the continuous increase of the twin volume fraction [3-7]. Unfortunately, no experimental determination of the local stress of the twins has been possible up to now, by X-ray diffraction for instance, due to two main difficulties: the thickness of the twins is very small (20 to $200 \mathrm{~nm}$ ) and the twins and the matrix present the same chemical composition and crystallographic structure. The determination of these characteristics is of prime importance in order to improve the understanding of the relationship between the microstructure evolution and the mechanical properties of FeMnC TWIP steels. A methodology suitable to provide a range of local stress within the twins is thus reported in this study. The determined values are discussed in regards of known plasticity relaxation mechanisms.

\section{Experimental Results}

This study focuses on a TWIP steel containing $1.2 \mathrm{wt} . \%$ of carbon and 20 wt.\% of manganese. This austenitic alloy is completely stable at room temperature (i.e. no strain-induced $\varepsilon$-martensite is observed) with the activation of mechanical twinning during straining. The grain size of the cold rolled and annealed $1.4 \mathrm{~mm}$ thick sheets is around $20 \mu \mathrm{m}$ [7]. The mechanical behaviour along a non-monotonic strain-path has been investigated by reverse shear tests. The experimental procedure is described in detail elsewhere [8]. (Figure 1) shows the different Bauschinger tests that were performed. The reverse shear curves are represented with a positive flow stress and their corresponding accumulated forward-backward strain. The monotonic simple shear curve is also represented on this Figure. These curves are used to measure the Bauschinger effect $\mathrm{BE}$ and the back-stress $\mathrm{s}_{\mathrm{b}}$ given by:

$$
\sigma_{\mathrm{b}}=\frac{\sigma_{\mathrm{f}}-\sigma_{\mathrm{r}}}{2}
$$




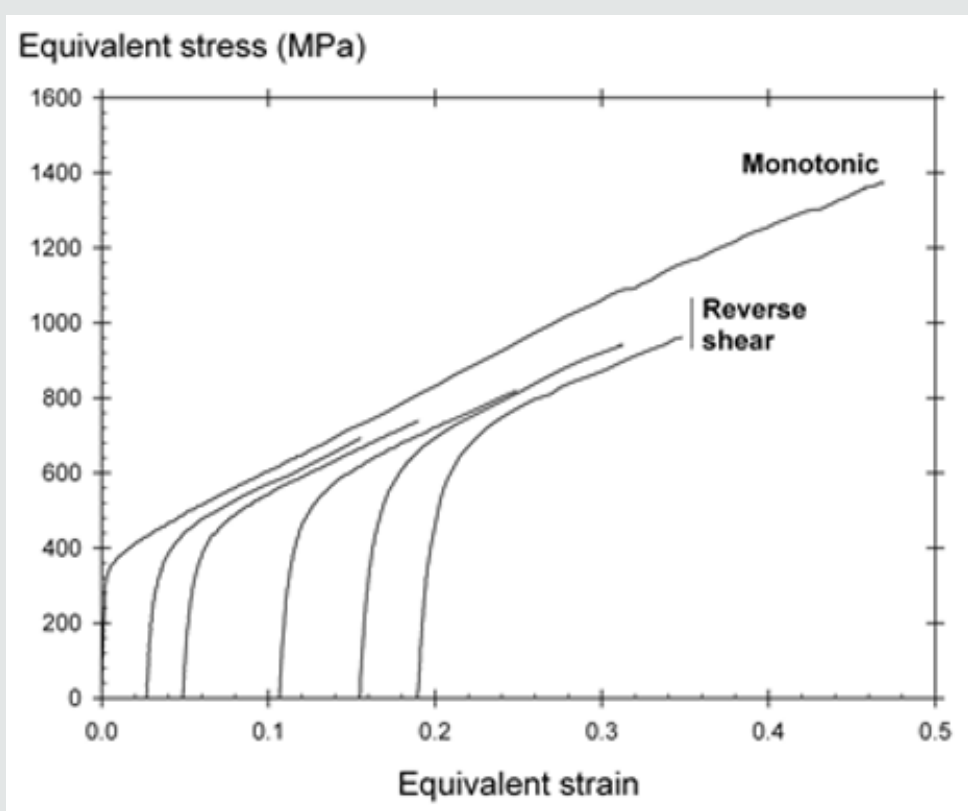

Figure 1: Stress-strain curves of monotonic simple shear and reverse shear loading after different forward prestrain. Reverse curves are shown with a positive flow stress.

The evolution of the back-stress as a function of plastic prestrain is illustrated in (Figure 2) for offsets of $0.2 \%, 0.5 \%$ and $1 \%$, respectively. It appears that the back-stress (i.e. the kinematic hardening) contributes up to half of the total strain-hardening which is consistent with previously reported results $[3,4]$. Such a large contribution can be described thanks to the microstructure evolution with strain of this TWIP steel, particularly the twin volume fraction and the characteristics of these twins. Indeed, the twin volume fraction has been measured following a procedure reported in [9]. In the case of simple shear loading, the volume fraction of twins has been determined at levels of equivalent strain of 0.1 and 0.2 [10]. Table 1 summarizes the characteristics estimated at these two levels of straining. Finally, it is worth noting that the twin thickness in the present TWIP steel has been estimated by transmission electron microscopy in the range 20 to $200 \mathrm{~nm}[11,12]$. Whatever the strain-hardening modelling $[3,5,6]$, the general expression for the back stress (or kinematic hardening) resulting from the twins considered as a reinforcing phase is given by [13]:

$$
\sigma_{\mathrm{b}}=\mathrm{F} \cdot(1-\mathrm{F}) \cdot\left(\sigma_{\mathrm{T}}-\sigma_{\mathrm{M}}\right)
$$

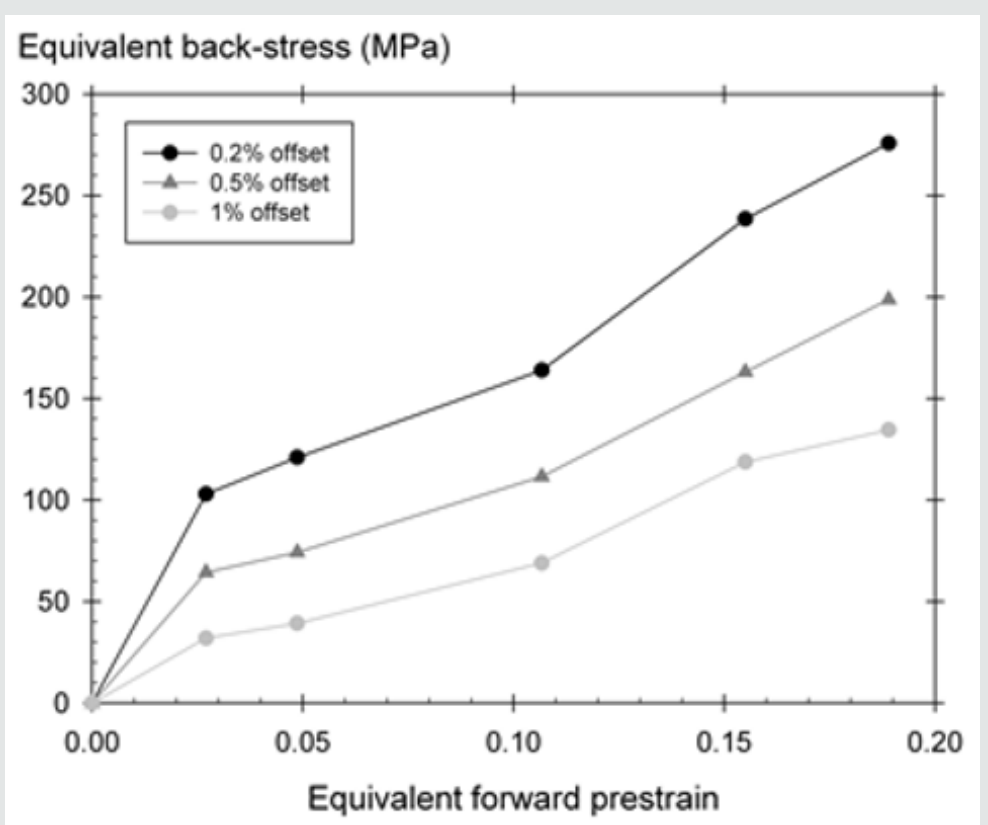

Figure 2: Evolution of back-stress (as estimated by Eq.1) as a function of forward strain for different offsets. 


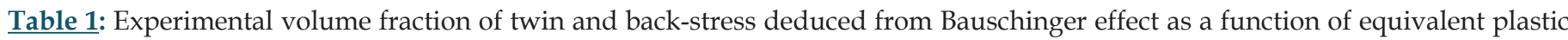
strain.

\begin{tabular}{|c|c|c|c|c|}
\hline Equivalent Strain & Twin Volume Fraction & Equivalent Stress (MPa) & $\begin{array}{c}\text { Back-Stress (0.2\%offset) } \\
\text { (MPa) }\end{array}$ & $\begin{array}{c}\text { Back-Stress (0.5\%offset) } \\
\text { (MPa) }\end{array}$ \\
\hline 0.1 & 0.09 & 600 & 170 & 115 \\
\hline 0.2 & 0.11 & 800 & 275 & 200 \\
\hline
\end{tabular}

where $\mathrm{F}$ is the volume fraction of twins, $\sigma_{\mathrm{T}}$ is the average local stress within these twins and $\sigma_{\mathrm{M}}$ is the average stress within the untwined matrix. Furthermore, mechanical equilibrium imposes that

$$
\sigma=(1-\mathrm{F}) \cdot \sigma_{\mathrm{M}}+\mathrm{F} \cdot \sigma_{\mathrm{T}}
$$

Where $\sigma$ is the total flow stress. The average local stress within twins can therefore be expressed as a function of the measured stresses as:

$$
\sigma_{\mathrm{T}}=\frac{\sigma_{\mathrm{b}}}{\mathrm{F}}+\sigma
$$

And the average stress within the untwined matrix is:

$$
\sigma_{\mathrm{M}}=\frac{\sigma-\mathrm{F} \cdot \sigma_{\mathrm{T}}}{1-\mathrm{F}}
$$

The values of $\sigma_{\mathrm{T}}$ and $\sigma_{\mathrm{M}}$ are summarised in Tables $2 \& 3$ respectively. The evolutions of these stresses with the equivalent plastic prestrain are also drawn in (Figures 3\&4). It is worth noting that the ratio between the local stress within twins $\sigma_{\mathrm{T}}$ and the total flow stress $\sigma$ is constant and equal to about 3.6. It is worth noting that the determined local stress within the twins lies in the range of

$$
\frac{\mathrm{E}}{100} \leq \sigma_{\mathrm{T}} \leq \frac{\mathrm{E}}{\theta}
$$

Table 2: Local stress within twins in MPa as a function of the plastic prestrain and of the chosen offsets deduced from Bauschinger tests and measured twin volume fractions.

\begin{tabular}{|c|c|c|}
\hline Equivalent Strain & Stress Within Twins (0.2\%offset) & Stress Within Twins (0.5\%offset) \\
\hline 0.1 & 2489 & 1878 \\
\hline 0.2 & 3191 & 2539 \\
\hline
\end{tabular}

Table 3: Local stress within the matrix in MPa as a function of the plastic prestrain and of the chosen offsets deduced from Bauschinger test and measured twin volume fractions.

\begin{tabular}{|c|c|c|}
\hline Equivalent Strain & Stress Within the Matrix (0.2\%offset) & Stress Within the Matrix (0.5\%offset) \\
\hline 0 & 320 & 320 \\
\hline 0.1 & 413 & 474 \\
\hline 0.2 & 489 & 574 \\
\hline
\end{tabular}

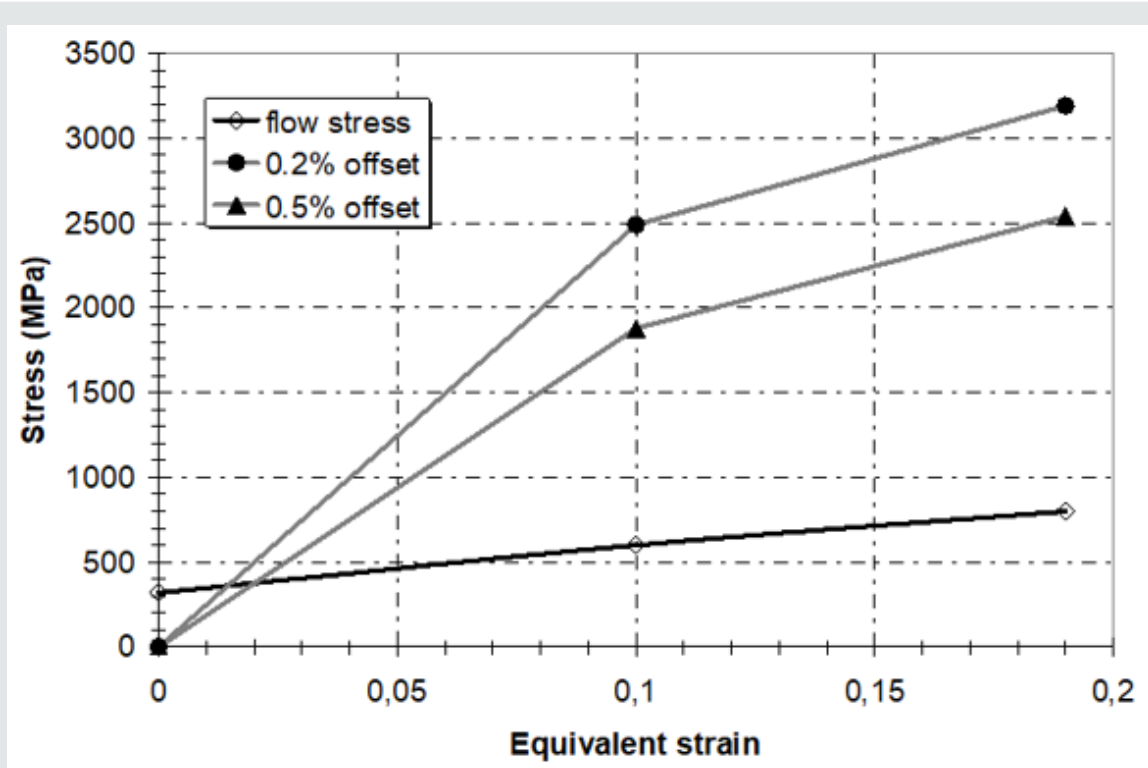

Figure 3: Evolution of the local stress within twins $\sigma_{\mathrm{T}}$ and flow stress $\sigma$ as a function of equivalent strain deduced from Bauschinger test and measured twin volume fractions. 


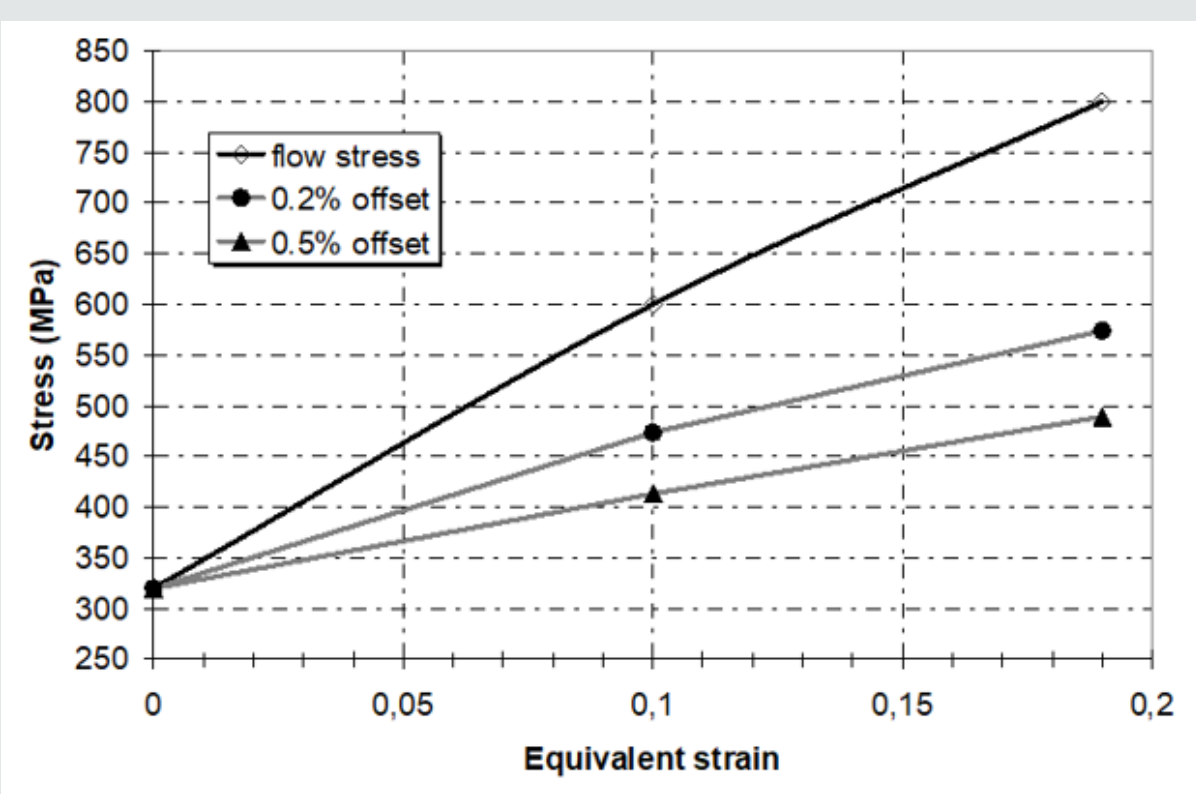

Figure 4: Evolution of the local stress within the matrix $\sigma_{M}$ and flow stress $\sigma$ as a function of equivalent strain.

where $\mathrm{E}$ is the Young modulus of 195GPa consistent with the paramagnetic state at room temperature related to the chemical composition of the investigated alloy. These bounds correspond to $1 / 3$ to $1 / 2$ of the theoretical strength for plasticity without any dislocation or for theoretical fracture stress. If plastic relaxation within twins was the emission of a dislocation, the maximum local stress would correspond to the critical stress for dislocation bowing to the critical Orowan configuration [14]

$$
\sigma_{\mathrm{T}}=\frac{M \cdot \mu \cdot b}{\mathrm{e}}
$$

Using the values reported in Table 2, the twin thickness corresponding to $s_{t}$ is close to $20 \mathrm{~nm}$, i.e. the lower bound of the measured thicknesses [11,12]. Conversely, a twin thickness of $200 \mathrm{~nm}$ would bring about a critical stress around $200 \mathrm{MPa}$, which is much smaller than the estimated twin stress (and also smaller than the yield strength). That means that the mechanical twins in TWIP steels present an internal structure strongly hindering dislocation glide as it was experimentally reported in [12] with a large density of sessile dislocations. Since the knowledge of the level of local stress within twins is crucial for significantly improving the understanding of the microstructure - properties relationships of FeMnC TWIP steels, a methodology suitable to determine this parameter has been developed. Experimental determination of the Bauschinger effect and the twin volume fraction combined with a suitable analysis provides for the first time the determination of the local stress within twins in Twinning Induced Plasticity (TWIP) steels. It is reported that this local stress increases as a function of plastic strain and is rapidly larger than $2 \mathrm{GPa}$ and can be probably larger than $3 \mathrm{GPa}$ for strains larger than 0.2 . Twin stresses range between 30 to $50 \%$ of the ultimate theoretical strength and the critical stress for the emission of a dislocation, a level compatible with the reported twin internal structure. Finally, it was observed that the ratio between the local stress within twins $\sigma_{\mathrm{T}}$ and the total flow stress $\sigma$ is constant and equal to about 3.6.

\section{Acknowledgement}

The author thanks Dr. F Levy for stimulating discussions.

\section{References}

1. Hadfield's Manganese Steel (1888) Science 12(306): 284-286.

2. Bouaziz O, Allain S, Scott C, Cugy P, Barbier D (2011) High Manganese Austenitic Twinning Induced Plasticity Steels: A Review of the Microstructure Properties Relationships. Current Opinion in Solid State and Materials Science 15(4): 141-168.

3. Bouaziz O, Allain S, Scott C (2008) Effect of grain and twin boundaries on the hardening mechanisms of twinning-induced plasticity steels. Scripta Mat 58(6): 484-487.

4. Gutierrez Urrutia I, Del Valle Ja, Zaefferer S, Raabe D (2010) Study of Internal Stresses in A Twip Steel Analyzing Transient and Permanent Softening During Reverse Shear Tests J Mater Sci 45: 6604-6610

5. Sevillano JG, F de las Cuevas (2012) Internal stresses and the mechanism of work hardening in twinning-induced plasticity steels. Scripta Mat 66(12): 978-981.

6. Rémy L (1978) Kinetics of f.c.c Deformation Twinning and Its Relationship to Stress-Strain Behaviour Acta Metallurgica 26(3): 443451.

7. Renard K, Ryelandt S, Jacques PJ (2010) Mater Sc Eng A 527: 2969.

8. Bouvier S, Haddadi H, Levée P, Téodosiu C (2006) J Mat Proc Tech 172: 96.

9. Renard K, Jacques PJ (2012) Mater Sc Eng A 542: 8-14.

10. Renard K, Idrissi H, Schryvers D, Jacques PJ (2012) On the stress state dependence of the twinning rate and work hardening in twinninginduced plasticity steels. Scripta Mater 66: 966-971.

11. Idrissi H, Renard K, Schryvers D, Jacques PJ (2010) On the relationship between the twin internal structure and the work-hardening rate of TWIP steels. Scripta Mater 63: 961-964. 
12. Idrissi H, Renard K, Ryelandt L, Schryvers D, Jacques PJ (2010) On the mechanism of twin formation in Fe-Mn-C TWIP steels Acta Mater 58(7): 2464-2476.

13. Allain S, Bouaziz O (2008) Mat Sc Eng A 496: 329.

(c)

This work is licensed under Creative

Commons Attribution 4.0 License

To Submit Your Article Click Here: Submit Article

DOI: $10.32474 / M A M S .2020 .02 .000141$
14. Gil J Sevillano (2009) An alternative model for the strain hardening of FCC alloys that twin, validated for twinning-induced plasticity steel. Scripta Mater 60(5): 336-339.

\begin{tabular}{l}
$\begin{array}{c}\text { Modern Approaches on } \\
\text { Material Science }\end{array}$ \\
Assets of Publishing with us \\
- Global archiving of articles \\
\hline - Immediate, unrestricted online access \\
- Rodern Approaches On \\
- Auterial Science
\end{tabular}

